\title{
Effects of steroid blockers on LH-induced ovulation in the domestic fowl, Gallus domesticus
}

\author{
H. Tojo and T. M. Huston* \\ Department of Animal Science, Kagoshima University, Korimoto 1, 21-24 Kagoshima, \\ Japan 890, and * Department of Poultry Science, University of Georgia, Athens, Georgia 30602, \\ U.S.A.
}

\begin{abstract}
Summary. The spontaneous ovulation of hens was suppressed by daily injection of PMSG. The LH injected to overcome the block was accompanied by one of 4 compounds known to inhibit steroidogenesis at different sites in the biosynthetic pathway. A dose of $300 \mathrm{mg}$ aminoglutethimide phosphate, which inhibits the conversion of cholesterol to $20 \alpha$-hydroxycholesterol, blocked the $\mathrm{LH}$-induced ovulation and prevented the normal rise in plasma progesterone. Metyrapone, an inhibitor of $11 \beta$-hydroxylase, and SC 12937 and AY 9944, inhibitors of cholesterol synthesis, did not prevent ovulation or the progesterone rise induced by exogenous LH. Administration of progesterone overcame the inhibitory effect of aminoglutethimide, and it is suggested that progesterone is involved in the ovulatory process of the fowl.
\end{abstract}

\section{Introduction}

It has been suggested that in the domestic fowl progesterone may induce the release of $\mathbf{L H}$ required for ovulation by stimulating the hypothalamus (Fraps \& Dury, 1943; Ralph \& Fraps, 1959, 1960; Wilson \& Sharp, 1976). Measurements of plasma LH and progesterone concentrations during the ovulatory cycle seem to support this suggestion (Peterson \& Common, 1971; Kappauf \& Van Tienhoven, 1972; Furr, Bonney, England \& Cunningham, 1973; Haynes, Cooper \& Kay, 1973; Wilson \& Sharp, 1973; Laguë, Van Tienhoven \& Cunningham, 1975; Shahabi, Norton \& Nalbandov, 1975; Shodono, Nakamura, Tanabe \& Wakabayashi, 1975). Furr et al. (1973) reported that the rise in progesterone always preceded or occurred simultaneously with the LH increase. By contrast, Williams \& Sharp (1978) found that the preovulatory release of LH was accompanied by a large increase in the secretion of androgen and progesterone. It has also been reported that corticosteroids are involved in the ovulation of the hen (Van Tienhoven, 1961; Soliman \& Huston, 1974; Etches \& Cunningham, 1976; Etches, 1977; Wilson \& Lacassagne, 1978). However, the role of steroid hormones in the ovulatory mechanism is not well clarified. We therefore studied the possible significance of ovarian steroid hormones in the ovulatory process of domestic hens by using compounds that are known to block steroid synthesis.

\section{Materials and Methods}

\section{Experiments}

The compounds used to block steroid synthesis at different sites were aminoglutethimide phosphate, metyrapone (provided from CIBA Pharmaceutical Company), AY 9944 (trans- 
1-4-bis-[2-chlorobenzylaminomethyl]-cyclohexane dihydrochloride, provided by Dr D. Dvornik, Ayerst Research Laboratories) and SC 12937 (20,25-diazacholesterol dihydrochloride, provided by, Dr R. N. Saunders, Searle Laboratories).

White Leghorn laying hens with 4 or 5 eggs in a clutch were used. The hens were kept in individual cages and exposed to $14 \mathrm{~h}$ light/day (06:00-20:00 h). Food and water were provided ad libitum. The regimen of PMSG and LH injections was as reported by Imai (1973): 80 i.u. PMSG (Ferring AB, Malmo, Sweden) were injected subcutaneously daily to suppress the spontaneous ovulation. At 22:00 h on the third day after cessation of egg laying and $24 \mathrm{~h}$ after the final injection of PMSG, LH (NIH-LH-B 10) was injected intravenously alone or with one of the inhibitory compounds. The compounds were given as 2 subcutaneous injections at 0 and 45 min after LH injection or as 3 injections at 0,30 and 60 min after LH injection. Hens which had been given aminoglutethimide were also given a subcutaneous injection of $15 \mathrm{mg}$ oestradiol or progesterone immediately after the $\mathrm{LH}$ injection. Control birds were injected with saline solution $(9 \mathrm{~g} \mathrm{NaCl} / \mathrm{l})$ instead of $\mathrm{LH}$. The total dose of each compound (150 mg SC 12937; $300 \mathrm{mg}$ for each of the others) was based on preliminary tests with up to $400 \mathrm{mg}$ of each drug administered to 2 hens; both hens died after a dose of $250 \mathrm{mg} \mathrm{SC} 12937,400 \mathrm{mg}$ metyrapone and $400 \mathrm{mg}$ AY 9944. AY 9944 and the hormones were suspended in corn oil, the other 3 drugs were dissolved in distilled water. Blood was collected from the wing vein immediately before LH or control injection and 30,60 and 90 min later. The plasma was separated by centrifugation at $4^{\circ} \mathrm{C}$ and stored at $-20^{\circ} \mathrm{C}$ until used. The hens were killed $10 \mathrm{~h}$ after the $\mathrm{LH}$ injection and examined for ovulated ova. The ovaries were removed and ruptured follicles and large yellow follicles $>3 \mathrm{~cm}$ in diameter were counted. Hens which had extensive atresia of the follicles were excluded from the results.

\section{Steroid assays}

The plasma oestradiol and progesterone concentrations were determined by the radioimmunoassay previously validated (Tojo \& Huston, 1980).

$\left[2,4,6,7-{ }^{3} \mathrm{H}(\mathrm{N})\right]$ Oestradiol (sp. act. $115 \cdot 0 \mathrm{Ci} / \mathrm{mmol}$ ) and $\left[1,2,6,7 \cdot{ }^{3} \mathrm{H}(\mathrm{N})\right]$ progesterone (sp. act. $114.0 \mathrm{Ci} / \mathrm{mmol}$ ) were obtained from New England Nuclear Co. and used without further purification. An antiserum produced in a sheep against 1,3,5(10)-oestratrien-3,17-diol-6one-6-CMO-BSA was used at a final dilution of $1: 100000$. The antiserum produced in a rabbit against 4-pregnen-3,20-dione-3-CMO-BSA was used at a final dilution of 1:15000. The buffer used was $0.1 \mathrm{M}$ phosphate-buffered saline (PBS, pH 7.0) containing $0.1 \%$ gelatin. Bound steroids were separated by the dextran-coated charcoal method. The specificity of the antisera was tested by cross-reactivity with 12 different steroids. The antiserum to oestradiol cross-reacted $100 \%$ against oestradiol-17 $\beta, 17.8 \%$ against oestriol, $1.5 \%$ with oestrone and $<0.1 \%$ with progesterone, pregnenolone, testosterone, $17 \alpha$-hydroxyprogesterone, cortisone, corticosterone, hydroxycortisone, 5 $\alpha$-androsten-17 $\beta$-ol-3-one, $\Delta^{4}$-androsten-3-n-dione, and cholesterol. Cross-reactions of the progesterone antiserum were $100 \%$ with progesterone, $1.5 \%$ with $17 \alpha$-hydroxyprogesterone, $0.5 \%$ with pregnenolone and $<0.1 \%$ with the other steroids mentioned above. The least amount distinguished significantly from zero amount by $t$ test was $31 \mathrm{pg}$ oestradiol $-17 \beta / \mathrm{ml}$ and $39 \mathrm{pg}$ progesterone $/ \mathrm{ml}$. Recovery of the added oestradiol $-17 \beta$ from plasma was $84 \cdot 2 \pm 4 \cdot 7 \%(n=5,250 \mathrm{pg} / \mathrm{ml})$ and $83 \cdot 3 \pm 3 \cdot 8 \%(n=5,500 \mathrm{pg} / \mathrm{ml})$. Progesterone recovery was $87.2 \pm 5.2 \%(n=5,250 \mathrm{pg} / \mathrm{ml})$ and $83.3 \pm 5.2 \%(n=5,500 \mathrm{pg} / \mathrm{ml})$. The between-assay coefficient of variation was $<15 \%$ for both assays. The hormone concentrations of the samples were calculated by comparison to standard curves composed of 8 points ranging from 31 to $2000 \mathrm{pg} / \mathrm{ml}$ for oestradiol- $17 \beta$ and from 39 to $5000 \mathrm{pg} / \mathrm{ml}$ for progesterone. 


\section{Results}

The ability of the 4 compounds to prevent the ovulation induced by LH injection is shown in Table 1. The numbers of ovulated ova and of large yellow follicles remaining in the ovary indicated that the rate of follicular growth in the PMSG-treated hens was similar in all the groups. A dose of $200 \mu \mathrm{g} \mathrm{LH}$ induced ovulation in all the hens but $<200 \mu \mathrm{g}$ was not always

Table 1. Effects of aminoglutethimide phosphate (AGP), metyrapone, SC 12937 and AY 9944 on ovulation induced by exogenous LH in hens in which spontaneous ovulation was suppressed by PMSG treatment

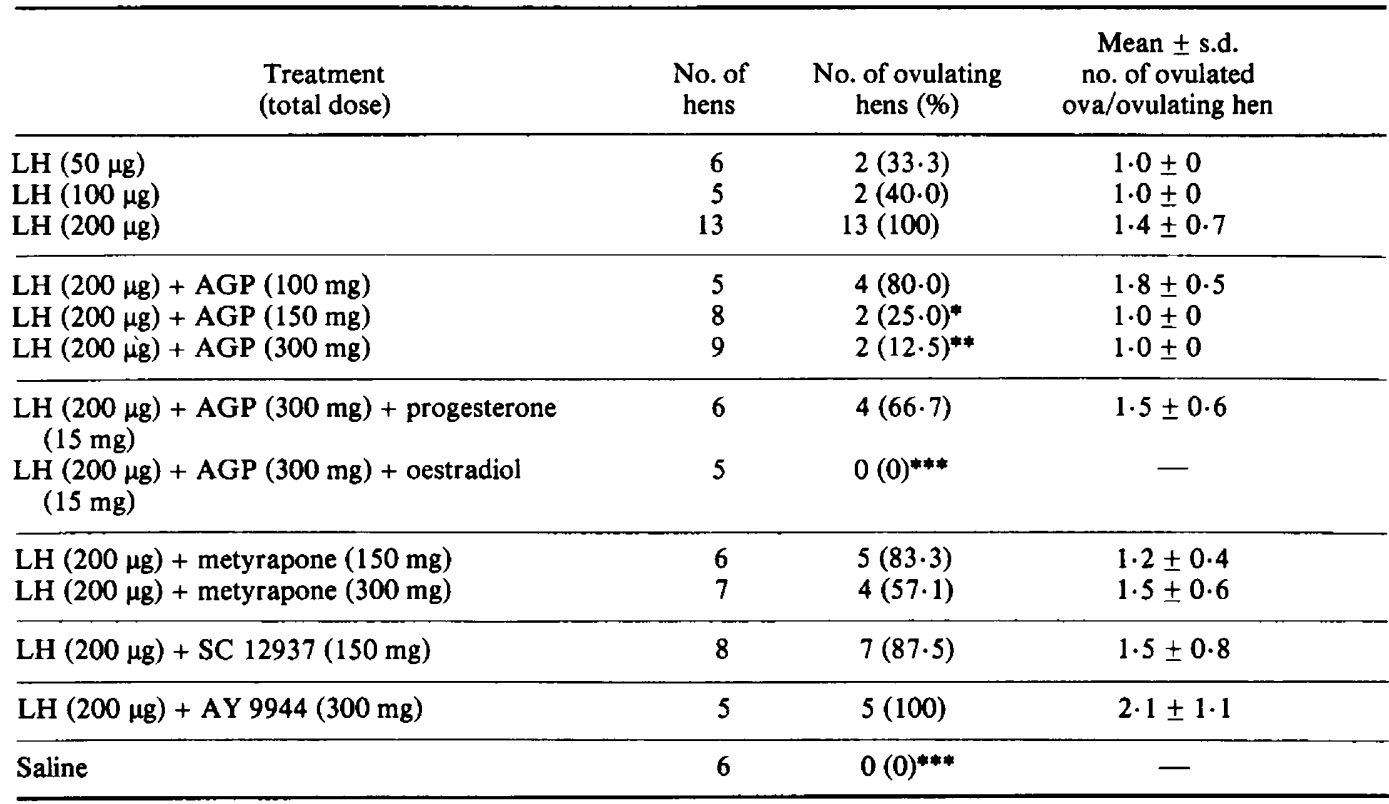

Values significantly different from that of $200 \mu \mathrm{g} \mathrm{LH}$ alone, ${ }^{*} P<0.05, * * P<0.01,{ }^{* * *} P<0.001$.

Table 2. Effects of aminoglutethimide phosphate (AGP), metyrapone, SC 12937 and AY 9944 on plasma oestradiol $\left(E_{2}\right)$ and progesterone $(P)$ concentrations (mean \pm s.e.m.) after LH injection $(200 \mu \mathrm{g})$ in hens in which spontaneous ovulation was suppressed by PMSG treatment

\begin{tabular}{lcccccc}
\hline & & \multicolumn{4}{c}{ Plasma hormone conc. (pg/ml) } \\
\cline { 3 - 6 } \multicolumn{2}{c}{ Treatment } & No. of & & \multicolumn{4}{c}{ hens } & Hormone & $0 \mathrm{~min}$ & $30 \mathrm{~min}$ & $60 \mathrm{~min}$ & $90 \mathrm{~min}$ \\
\hline LH & 9 & $\mathrm{E}_{2}$ & $708 \pm 81$ & $721 \pm 81$ & $715 \pm 45$ & $670 \pm 48$ \\
& & $\mathbf{P}$ & $1130 \pm 110$ & $2062 \pm 170^{* * *}$ & $2130 \pm 185^{* * *}$ & $1685 \pm 160^{*}$ \\
LH + AGP (300 mg) & 7 & $\mathrm{E}_{2}$ & $583 \pm 24$ & $362 \pm 32$ & $345 \pm 28$ & $342 \pm 25$ \\
& & $\mathbf{P}$ & $1095 \pm 85$ & $1135 \pm 78$ & $1093 \pm 95$ & $1114 \pm 140$ \\
LH + metyrapone (300 mg) & 5 & $\mathrm{E}_{2}$ & $781 \pm 65$ & $754 \pm 40$ & $692 \pm 43$ & $723 \pm 25$ \\
& & $\mathbf{P}$ & $1220 \pm 65$ & $2115 \pm 140^{* * *}$ & $2184 \pm 225^{* * *}$ & $1790 \pm 170^{*}$ \\
LH + SC 12937 (150 mg) & 6 & $\mathbf{E}_{2}$ & $683 \pm 72$ & $667 \pm 42$ & $773 \pm 63$ & $756 \pm 52$ \\
& & $\mathbf{P}$ & $1050 \pm 85$ & $1867 \pm 180^{* *}$ & $2013 \pm 162^{* *}$ & $1862 \pm 180^{* *}$ \\
LH + AY 9944 (300 mg) & 5 & $\mathrm{E}_{2}$ & $752 \pm 57$ & $702 \pm 50$ & $594 \pm 46$ & $832 \pm 32$ \\
& & $\mathbf{P}$ & $1153 \pm 75$ & $1952 \pm 102^{* * *}$ & $1894 \pm 162^{* *}$ & $1904 \pm 170^{* *}$ \\
Saline & 6 & $\mathrm{E}_{2}$ & $550 \pm 49$ & $620 \pm 38$ & $650 \pm 42$ & $902 \pm 26$ \\
& & $\mathbf{P}$ & $1035 \pm 65$ & $1197 \pm 72$ & $1145 \pm 45$ & $1150 \pm 81$ \\
\hline
\end{tabular}

Values significantly different from those at $0 \mathrm{~min}$ in each treatment; ${ }^{*} P<0.05,{ }^{* *} P<0.01,{ }^{* * *} P<0.001$ ( $t$ test). 
effective. Aminoglutethimide at a dose of $300 \mathrm{mg}$ was completely effective in preventing the ovulation, but ovulation occurred if progesterone (but not oestradiol) was also injected immediately after the LH. Metyrapone prevented ovulation in only a few of the hens and SC 12937 and AY 9944 were also ineffective. The concentrations of plasma oestradiol and progesterone in the treated hens are shown in Table 2. A significant rise in progesterone concentration was obtained after the injection of LH alone, metyrapone, SC 12937 and AY 9944. The peak value was at 30 or $60 \mathrm{~min}$ after the $\mathrm{LH}$ injection. Aminoglutethimide injection prevented the plasma progesterone rise but oestradiol concentrations were lower after treatment than in the other groups of hens.

\section{Discussion}

Aminoglutethimide was the only compound able to suppress the LH-induced ovulation and the increase in plasma progesterone levels caused by LH injection. Aminoglutethimide is reported to prevent the conversion of cholesterol to $20 \alpha$-hydroxycholesterol (Kahnt \& Neher, 1966) and it is possible that this was the site of action in the treated hens, in which plasma oestradiol concentrations were also decreased. However, the ovulation blocked by aminoglutethimide could be overcome by a single injection of progesterone, indicating that progesterone may be involved in the subsequent ovulatory process after sensitization of the mature follicle by LH. Oestradiol appeared not to be an essential steroid in relation to follicular rupture. The results support those of Lipner \& Greep (1971) who found that a high dose of aminoglutethimide was effective in blocking ovulation induced by exogenous LH in immature rats primed with PMSG and that an agent which inhibited progesterone synthesis significantly blocked the induced ovulation. As in the domestic fowl (Shahabi, Bahr \& Nalbandov, 1975; Imai \& Nalbandov, 1978), plasma progesterone values are also significantly increased in rats and rabbits shortly after a rise in endogenous LH or LH injection (Labhsetwar, Joshi \& Watson, 1973; Shaikh \& Harper, 1972), indicating a similar ovulatory mechanism. However, in the domestic fowl, it has been suggested that progesterone induces ovulation through stimulating the hypothalamus (Fraps \& Dury, 1943; Ralph \& Fraps, 1959, 1960; Wilson \& Sharp, 1976). Williams \& Sharp (1978) reported that there was first an increase in LH level which caused a small rise in plasma androgen and progesterone while the preovulatory release of $\mathrm{LH}$ was accompanied by a much larger increase in the secretion of these steroids. This suggests that a large increase in progesterone after LH release is associated with the follicular rupture.

Metyrapone inhibits the hydroxylase that converts $11 \beta$-deoxycorticosterone to corticosterone (Liddle, Island, Lance \& Harris, 1958). In this study, metyrapone had no significant effect on the block to ovulation although corticosteroids are able to induce ovulation in the hen (Van Tienhoven, 1961; Soliman \& Huston, 1974; Etches \& Cunningham, 1976; Etches, 1977; Wilson \& Lacassagne, 1978). Therefore, the results of metyrapone injection did not indicate any involvement of the adrenal in the LH-induced ovulation and it is possible that the injected adrenal steroids will be converted to progesterone or other steroids. SC 12937 and AY 9944 are considered to prevent cholesterol synthesis (Counsell, Klimstra, Ranney \& Cook, 1962; Dvornik, Kraml, Dubuc, Givner \& Gaudry, 1963). Daily administration of AY 9944 also caused the cessation of egg laying accompanied by decrease in blood cholesterol (Martin \& Lupien, 1969). In the present study, neither compound affected the ovulation or the rise in progesterone level induced by LH, in spite of the almost lethal dose used. Lipner \& Greep (1971) reported that AY 9944 was not effective in preventing ovulations in rats. Prevention of cholesterol synthesis therefore does not affect the ovulatory process after sensitization of the mature follicle by LH. We conclude that in the domestic fowl progesterone may be an important steroid in the ovulatory process after sensitization of the mature follicle by $\mathrm{LH}$, probably in the synthesis or activation of the enzyme required for follicular rupture. 
This work was financed by the Experimental Station, College of Agriculture, University of Georgia. We thank Dr D. N. Marple, Auburn University, for the antioestradiol serum; Dr F. J. N. Thompson, University of Georgia, for the antiprogesterone serum; Dr R. R. Kraeling, Richard B. Russell Agricultural Research Center (U.S.D.A), for helpful advice on the RIA; NIH for gifts of bovine LH; CIBA Pharmaceutical Company (New Jersey) for aminoglutethimide phosphate and metyrapone; Dr D. Dvornik, Ayerst Research Laboratories (Montreal, Canada), for AY 9944; and Dr R. N. Saunders, Searle Laboratories (Chicago) for SC 12937.

\section{References}

Counsell, R.E., Klimstra, P.E., Ranney, R.E. \& Cook, D.L. (1962) Hypocholesterolemic agents. I. 20(2-dialkl-aminoethylamino) pregn-5-en-3 $\alpha$-ol derivatives. J. Med. Pharm. Chem. 5, 720-729.

Dvornik, D., Kraml, M., Dubuc, J., Givner, M. \& Gaudry, R. (1963) A novel mode of inhibition of cholesterol biosynthesis. J. Am. Chem. Soc. 85, 3309.

Etches, R.J. (1977) The temporal relationship between ovulation and an injection of progesterone or corticosterone in the hen, Gallus domesticus. Biol. Reprod. 16, 255-257.

Etches, R.J. \& Cunningham, F.J. (1976) The effect of an injection of pregnenolone, progesterone, deoxycorticosterone or corticosterone on the time of ovulation and oviposition in the chicken. Br. Poult. Sci. 17, 637-642.

Fraps, R.M. \& Dury, A. (1943) Occurrence of premature ovulation in the domestic fowl following administration of progesterone. Proc. Soc. exp. Biol. Med. 52, 346-349.

Furr, B.J.A., Bonney, R.C., England, R.J. \& Cunningham, FJ. (1973) Luteinizing hormone and progesterone in peripheral blood during the ovulatory cycle of the hen Gallus domesticus. J. Endocr. 57, 159-169.

Haynes, N.B., Cooper, K.J. \& Kay, M.J. (1973) Plasma progesterone concentration in the hen in relation to the ovulatory cycle. Br. Poultry Sci. 14, 349-357.

Imai, K. (1973) Effects of avian and mammalian pituitary preparations on induction of ovulation in the domestic fowl, Gallus domesticus. J. Reprod. Fert. 33, 91-98.

Imai, K. \& Nalbandov, A.V. (1978) Plasma and follicular steroid level of laying hens after the administration of gonadotropins. Biol. Reprod. 19, 779-784.

Kahnt, F.W. \& Neher, R. (1966) Über die adrenale steroidbiosynthese in vitro. III. Selective hemmuny der nebennierenrinden. Helv. Chir, Acta 49, 725732.

Kappauf, B. \& Van Tienhoven, A. (1972) Progesterone concentration in peripheral plasma of laying hens in relation to the time of ovulation. Endocrinology $\mathbf{9 0}$, $1350-1355$.

Labhsetwar, A.P., Joshi, H.S. \& Watson, D. (1973) Temporal relationship between estradiol, estrogen and progesterone secretion in the ovarian venous blood and LH in peripheral blood. Biol. Reprod. 8, 321-326.
Laguë, P.C.A., Van Tienhoven, A. \& Cunningham, F.J. (1975) Concentration of estrogen, progesterone and LH during the ovulatory cycle of the laying chicken. Biol. Reprod. 12, 590-598.

Liddle, G.W., Island, D., Lance, E.M. \& Harris, A.P. (1958) Alterations of adrenal steroid patterns in man resulting from treatment with a chemical inhibitor of $11 \beta$-hydroxylation. J. clin. Endocr. Metab. 18, 906-911.

Lipner, H. \& Greep, R.O. (1971) Inhibition of steroidogenesis at various sites in the biosynthetic pathway in relation to induced ovulation. Endocrinology 88, 602-617.

Martin, G.B. \& Lupien, P.J. (1969) Some biochemical and physiological effects of AY 9944 on laying hens. Can. J. Physiol. Pharmac. 47, 281-290.

Peterson, A.J. \& Common, R.H. (1971) Progesterone concentration in peripheral plasma of laying hens as determined by competitive protein binding assay. Can. J. Zool. 50, 395-404.

Ralph, C.L. \& Fraps, R.M. (1959) Effect of hypothalamic lesions on progesterone-induced ovulation in the hens. Endocrinology 65, 819-824.

Ralph, C.L. \& Fraps, R.M. (1960) Induction of ovulation in the hen by injection of progesterone into the brain. Endocrinology 66, 269-272.

Shahabi, N.A., Norton, H.W. \& Nalbandov, A.V. (1975) Steroid levels in follicles and the plasma of hens during the ovulatory cycle. Endocrinology 96, 962968.

Shahabi, N.A., Bahr, J.M. \& Nalbandov, A.V. (1975) Effect of $\mathbf{L H}$ injection on plasma and follicular steroid in the chicken. Endocrinology 96, 969-972.

Shaikh, A.A. \& Harper, M.J.K. (1972) Ovarian steroid secretion in estrous, mated and HCG-treated rabbits, determined by concurrent cannulation of both ovarian veins. Biol. Reprod. 7, 387-396.

Shodono, M., Nakamura, T., Tanabe, Y. \& Wakabayashi, K. (1975) Simultaneous determinations of oestradiol-17 $\beta$, progesterone and luteinizing hormone in the plasma during the ovulatory cycle of the hen. Acta endocr., Copenh. 78, 565-573.

Soliman, K.F.A. \& Huston, T.M. (1974) Involvement of the adrenal gland in ovulation of the fowl. Poultry Sci. 53, 1664-1667.

Tojo, H. \& Huston, T.M. (1980) Effects of environmental temperature on the concentration of serum estradiol, progesterone and calcium in maturing female domestic fowl. Poultry Sci. 59 (in press). 
Van Tienhoven, A. (1961) The effect of massive doses of corticotropins and of corticosterone on ovulation of the chicken (Gallus domesticus). Acta endocr., Copenh. 38, 407-412.

Williams, J.B. \& Sharp, P.J. (1978) Control of the preovulatory surge of luteinizing hormone in the hen (Gallus domesticus). The role of progesterone and androgen. J. Endocr. 77, 57-65.

Wilson, S.C. \& Sharp, P.J. (1973) Variations in plasma LH levels during the ovulatory cycle of the hen, Gallus domesticus. J. Reprod. Fert. 35, 561-564.
Wilson, S.C. \& Sharp, P.J. (1976) The effects of progesterone on oviposition and ovulation in the domestic fowl (Gallus domesticus). Br. Poult. Sci. 17, 163-173.

Wilson, S.C. \& Lacassagne, L. (1978) The effects of dexamathasone on plasma luteinizing hormone and oviposition in the hen. Gen. comp. Endocr. 35, 16-26.

Received 13 May 1980 